\title{
USING LABORATORY EXPERIMENTS TO TEST THEORIES OF CORPORATE BEHAVIOR
}

\author{
Satoshi Kanazawa
}

\begin{abstract}
Laboratory experiments provide the most rigorous method of testing scientific theories. However, their current use is primarily limited to testing theories of individual behavior. I suggest the conditions under which one can test theories of corporate behavior in laboratory experiments, using human subjects in the role of purposive corporate actors (such as groups or the state). Using the Condorcet Jury Theorem, I demonstrate that, when four conditions are met, laboratory experiments with human subjects represent statistically conservative tests of such theories. I address the issue of 'external validity' and argue that it is not a concern for laboratory experiments as a means of testing theories with clearly stated scope conditions. Finally, I point out that, contrary to popular belief, supermajority decision rules, used by juries and legislatures alike presumably for more important decisions, actually lead to inferior collective decisions.
\end{abstract}

KEY WORDS • laboratory experiments $\bullet$ Condorcet Jury Theorem • methodology $\bullet$ superiority of collective decisions $\bullet$ inferiority of supermajorities

\section{Introduction}

Laboratory experiments provide the most rigorous testing of hypotheses derived from general and abstract theories. ${ }^{1}$ By allowing maximal control over extraneous variables through randomization, the experiment provides the most unambiguous evidence for causation, and thus for confirmation or disconfirmation of causal hypotheses (Aronson et al. 1985: 443). Methodologists generally concur that experimental data, where possible, are better than non-experimental data for causal inference (Costner and Leik 1964: 824-5; Costner and Blalock 1972: 836; Arminger and Bohrnstedt 1987: 370; Berk 1988: 155; Sobel 1996: 372-3). Some even go so far as to claim that causes are only those things

Rationality and Society Copyright (C) 1999 Sage Publications (London, Thousand Oaks, CA and New Delhi), Vol. 11(4): 443-461. [1043-4631(199911)11:4; 443-461; 010136] 
that could, in principle, be treatments in experiments (Cook and Campbell 1979: 25-8; Holland 1986: 954).

Since laboratory experiments in social sciences use human subjects, however, their current use is primarily limited to testing theories of individual behavior. ${ }^{2}$ Yet many social theories are about behavior of corporate actors (groups, organizations, nation states). Some, like exchange theory, game theory and network theory, conceive of actors as both individual and corporate, and are meant to apply to both (Berger et al. 1989). ${ }^{3}$ These theories are often tested and supported in laboratory experiments. Yet there is no reason to believe that the experimental evidence, using human subjects, also supports the theories when actors are corporate. In this paper, I call for the use of laboratory experiments to test theories of corporate behavior. I will argue that, under reasonable conditions, human subjects may play the role of corporate actors to test theories about their behavior. There are two separate logical justifications for the use of laboratory experiments to test theories of corporate behavior.

Many have argued that an individual is not a singular entity but is composed of many parts or 'multiple selves' with conflicting interests. Abell (1989) speaks of the 'internal prisoner's dilemma' between the egoistic and altruistic motivations within a single individual. Schelling (1984) discusses the contest for self-command between "straight" ego" (with a low discount rate) and 'wayward alter' (with a high discount rate), in what Elster (1989) calls an intrapersonal collective action problem. Ainslie (1992) talks about successive motivational states within a single person, in his call for a new economics with smaller units of analysis than microeconomics: picoeconomics. If one can assume (as one does when testing theories of individual behavior in laboratory experiments with human subjects) that individuals can coordinate conflicting interests of these subunits within themselves and act rationally with a consistent preference hierarchy, then it is a mere logical extension to argue that corporate actors can coordinate conflicting interests of their subunits (individuals) and act rationally with a single preference hierarchy. ${ }^{4}$

I will not pursue this line of defense in this paper, however. Following Feld and Grofman (1990), I will instead emphasize the social and purposive nature of corporate actors. I will discuss how actors 'behave,' and two different types of groups, and argue that the only place where logical justification is necessary to test theories of corporate behavior in laboratory experiments is the process of decision making in democratic groups. Because the Condorcet Jury Theorem (CJT) (Condorcet 1785) 
demonstrates that under certain conditions collective decisions are always superior to individual decisions, using human subjects in laboratory experiments to test macro theories of corporate actors will provide statistically conservative tests of such theories.

\section{Two Stages of Behavior: Decision Making and Execution}

One can justifiably test a theory of corporate behavior in a laboratory experiment, with human subjects in the roles of corporate actors, if and only if one can show that individuals in the experiment are reasonable substitutes for the corporate actors in the theory with respect to the relevant experimental variables. If the human subjects react to experimental manipulations differently from how corporate actors react to the correspondent theoretical variables, the experimental test will neither confirm nor disconfirm the theory's hypotheses; it will just be irrelevant.

All behavior (of both individual and corporate actors) consists of two sequential stages: making a decision, and carrying out the decision. For individual behavior, both are performed by the same entity; the individual makes a decision, and then subsequently carries out the decision. For corporate behavior, regardless of how decisions are made for the group, they are always carried out by an individual, in typical principal-agent relations (Jensen and Meckling 1976; Friedman 1986; Petersen 1993). ${ }^{5}$ Groups cannot behave in the true sense of the word; only individuals can, as agents acting on behalf of groups (Lawler et al. 1993: 272n). So for the second stage of behavior, using human subjects in place of corporate actors in laboratory experiments entails no logical problem. In both laboratory experiments and natural settings, it is always the individual who carries out the decision, and human subjects are reasonable substitutes for the agents for corporate actors. ${ }^{6}$

The use of human subjects to model the first, decision-making stage of corporate behavior still needs to be justified. In terms of how groups make collective decisions, I can discern two ideal types of groups. (Note that these are ideal types, and groups in natural settings may be mixtures of the two.) In democratic groups, collective decisions reflect the individual decisions by all members. In dictatorial groups, 'collective decisions' are made by a single individual, the dictator. The use of human subjects to model the process of decision making in dictatorial groups once again presents no logical problem because the entity that makes the decision in laboratory experiments and the one that does so in natural settings are the same. This means that the only place that requires 
logical justification is the process of decision making in democratic groups. ${ }^{7}$

\section{Decision Making in Democratic Groups}

Condorcet (1976: 33-70) was the first to discuss the possibility of cyclical collective decisions. Under certain conditions, the aggregation of individual preferences results in a collective choice to which a majority prefers another choice. Assume that a collectivity faces three potential choices: $a, b$ and $c$. If a third of the collectivity has the transitive preference hierarchy $a>b>c$, a third has $b>c>a$ and another third $c>$ $a>b$, a two-thirds majority prefers $a$ to $b$, another two-thirds majority prefers $b$ to $c$ and another two-thirds majority prefers $c$ to $a$, making the collective choice intransitive, even though every single member of the collectivity holds a transitive preference hierarchy. Then, in his Nobel prizewinning work, Arrow (1963) demonstrates that there is no general method, with reasonable restrictions, of aggregating individual decisions to form a collective choice which avoids this cyclical pattern. In other words, there is no general method of always producing transitive collective preferences even when individual preferences are transitive.

Arrow's argument, however, assumes the existence of 'impartial culture' (Garman and Kamien 1968; Gehrlein and Fishburn 1976), where any individual preference ordering is as likely to happen in the population of voters as any other (Arrow 1963: 59; Plott 1967; Niemi and Weisberg 1968). ${ }^{8}$ Impartial culture is thus a random collection of voters with respect to preference orderings. But a group in natural settings is never a random collection of individuals. As Skog (1993: 207) notes, natural groups represent a very limited space in the universe of all mathematically possible collections of individual preferences. In natural settings, members of a group always share certain goals and purposes in common.

Natural groups are thus purposive and pursue certain collective goals. This observation has two implications. First, given a set of collective goals, certain group decisions are 'right' and others are 'wrong'. 'Right' group decisions are those that promote the group goals, and 'wrong' ones are those that hinder them. ${ }^{9}$ The fact that it is often difficult and sometimes impossible to tell whether a given group decision is a right one is inconsequential. A right decision is the one that an individual would make in light of full information. Second, because the raison 
d'être of a natural group is to achieve group goals, all group decisions ultimately pertain to the achievement of these goals. For instance, all decisions that a capitalist firm makes ultimately pertain to the pursuit of increasing profits and market shares.

Right and wrong decisions in this sense need not reflect any objective scientific reality. Group goals may be entirely socially constructed. Residents of Salem Village, Massachusetts, in the seventeenth century, decide to form a group for the purpose of finding and executing witches. In the minds of these people, witches exhibit certain behavioral traits. Then the decision to execute the person who exhibits these traits most frequently is the right decision, and the decision to execute another who exhibits them less frequently is the wrong decision, whether or not witches exist in reality. Note that people in Salem Village, with their limited information, may make a wrong decision and decide to execute the 'wrong' person, but someone with full information (a complete list of putative behavioral traits of witches and the actual behavioral traits of all persons in Salem Village at all times) can always make the right decision.

\section{The Superiority of Collective Decisions: The Condorcet Jury Theorem}

The CJT demonstrates that a majority of a democratic group is always better at choosing the superior of two alternatives than any single individual (Condorcet 1785; Black 1958: 164-5; McLean and Hewitt 1994: 34-40). In its original formulation, the CJT assumes the following conditions:

(1) there are exactly two alternatives,

(2) all individuals share a common preference such that one of the two alternatives is superior for all in light of full information,

(3) each individual makes the right decision with the probability $p>0.5$; individuals are homogeneous in $p$,

(4) the individual decisions are independent of one another,

(5) the collective decision rule is simple majority.

If all these conditions hold, then the probability that a majority of a group of size $n$ makes the right decision, $P_{n}$, is always greater than $p$, and very quickly approaches 1 as either $n$ or $p$ increases (see Ladha 1992: Appendix, for proof of CJT in its original formulation; see Miller 1986: 176, Table 1, for values of $P_{n}$ for selected values of $p$ and $n$ ).

An important implication of the CJT is that, if a natural group finds itself in an informational environment that would allow an individual to 
make the right decision with a certain probability $(p)$, then the group can always make the right decision with a higher probability $\left(P_{n}>p\right)$. This means that using human subjects to act as corporate actors to test theories of their behavior in laboratory experiments consistently underestimates the probability that the corporate actors will make the right decision. Then, as long as the theories being tested are based on the premise that groups are purposive actors, laboratory experiments always provide statistically conservative tests of the theories.

\section{What if There are More than Two Alternatives? (Relaxing Condition 1)}

The CJT even in its latest formulation (Kanazawa 1998) still technically requires that there be only two alternative choices. However, any multiple choice situation can be reduced to a binary choice situation by considering two at a time. If there are three potential choices (A, B, C), then the members of the collectivity can first vote on the choice between $\mathrm{A}$ and $\mathrm{B}$, then on the choice between the winner of the first vote and C. As I note above, the Condorcetian cycle will not occur when the corporate actor is purposive and its members share common interests.

\section{What if There Are No Right and Wrong Decisions? (Relaxing Condition 2)}

In a significant extension of the CJT, Miller (1986) demonstrates that it is not necessary for there to be 'right' and 'wrong' decisions for the CJT to work (see Miller 1986: 177-83 for proof). In other words, the theorem can be extended from 'juries' in the original formulation (where there are right and wrong decisions on which all jurors would agree in light of full information) to 'electorates' (where no such agreement may exist even in light of full information) (Miller 1986: 178). Miller (1986) shows that the probability that the majority opinion prevails, $P^{\prime}{ }_{n}$, is greater than the individual competence, $p$ (now redefined as the probability that individuals vote, under limited information, for their 'true' interest that they would vote for in light of full information) as long as $n$ is large. (Note that individuals may not always be able to vote for their true interest under limited information.) If one argues that the majority opinion is the 'right' decision for democracies, then a large group (electorate) is still better at making the right decision than individuals. Thus Condition 2 above (that there be right and wrong decisions) is not necessary for large groups. 


\section{What if Individuals are Not Homogeneous in Their p? (Relaxing Condition 3)}

Boland's (1989) extension of the CJT demonstrates that individuals need not be homogeneous in their competence in order for the CJT to work. In fact, for any given mean individual competence, heterogeneous groups are better at making the right decision than homogeneous groups (Kanazawa 1998). The only catch is that the mean individual competence must be at least $\frac{1}{2}+\frac{1}{2 n}$, rather than $\frac{1}{2}$ as in the original formulation. $\frac{1}{2}+\frac{1}{2 n}$ has a limit at $\frac{1}{2}$ as $n$ increases, so this is not a stringent condition for large groups. But for a group of three, for example, the mean individual competence must be at least 0.67 , and it must be at least 0.55 for a group of 10 . Note, however, that this is only a constraint on the mean; there can be individual members each with a significantly lower $p$ as long as there are others with significantly higher competence to bring up the mean.

\section{What if Individual Decisions are Not Independent? (Relaxing Condition 4)}

Ladha (1992) relaxes the condition in the original CJT that individual decisions be independent of one another, and extends it to cases where they are correlated. He demonstrates that the CJT holds even when individual decisions are correlated, as long as they are not too highly positively correlated. ${ }^{10}$ Thus the CJT holds, and a group is better than the mean individual at making the right decision, even when individual decisions are correlated as long as their correlation is not too high. In particular, it is important to note that Ladha's (1992) sufficient condition only sets the upper limit (in terms of positive correlations) and not the lower limit (in terms of negative correlations). In fact, negative correlations among individual decisions facilitate the superiority of collective decisions; groups where individual decisions are negatively correlated perform better than those where individual decisions are independent (Ladha 1995: Corollary 2), just like heterogeneous groups perform better than homogeneous groups (Kanazawa 1998: Theorem 1).

Estlund (1994) argues that interpersonal influence (where some individuals defer to others' opinions) does not necessarily eliminate independence of individual decisions. In particular, he demonstrates that, when the opinion leader to which individuals defer is outside of the group, independence of individual decisions holds as long as $p_{i}>f_{i}$, where $f_{i}=i$ 's fidelity to the opinion leader (a proportion of decisions 
where $i$ concurs with the opinion leader). For instance, if $i$ 's competence $p_{i}=0.7$, then independence holds as long as $i$ defers to the external opinion leader less than $70 \%$ of the time. Independence is violated only when deference is 'blind and partial', in that individuals defer to the opinion leader some of the time but randomly choose which times (Estlund 1994: 152-6). Independence holds if partial deference is 'wise', in that $p_{i}>f_{i}$.

What if the opinion leader is internal to the group? Estlund (1994: 158-9; personal communication) first points out that if the correlation between the decisions of two individuals is 1.0 (by always choosing the same alternative), then it is equivalent to treating these two individuals as one, and thereby reducing $n$ by 1 (Grofman and Feld 1988). Since $P_{n}$ increases with $n$, a perfect correlation thus decreases the group competence. Estlund further maintains that, if the correlation is less than 1.0, the damage to the group competence is less than if the correlation is 1.0. If individuals defer to an internal opinion leader to an unknown degree (but always $f_{i} \leq 1.0$ ), then the group competence, lowered by such interdependence of decisions, will be at least $P_{n-1}$ among the members who are not the opinion leader. In general, then, a conservative estimate of the group competence with interdependent decisions created by deference to internal opinion leaders is $P_{(n-m)}$, where $m=$ the number of opinion leaders. In essence, the interdependence of decisions due to deference to opinion leaders results in group competence as if opinion leaders do not exist, and making a collective decision among the remaining members. Thus the collective decision under such circumstances will still be superior to individual decisions as long as $n$ is large enough relative to the number of opinion leaders.

\section{What if a Group Uses a Supermajority Decision Rule? (Relaxing Condition 5)}

Kanazawa (1998) demonstrates that the CJT extends from simple majority rule to any supermajority rule, as long as the mean individual competence is at least $\frac{\pi(n+1)}{\mathrm{n}}$, where $\pi=$ the proportion required for collective decision ( $\pi=\frac{1}{2}$ for simple majority) (see Kanazawa 1998 for proof). Thus supermajority rules $\left(\pi>\frac{1}{2}\right)$ require higher mean individual competence. For instance, for a heterogeneous group of 100 (e.g. the US Senate), the mean individual competence can be as low as 0.505 for the group to be superior to the mean individual if the collective decision is simple majority. However, it must be at least 0.606 if the collective decision rule requires a three-fifths majority, and be at least 0.673 for a two-thirds majority. 


\section{Sufficient Conditions for Experimental Testing of Macro Theories}

To sum up, the CJT and its subsequent extensions suggest that, under the following four conditions, a collectivity is superior to an individual in making the right decision. Then, when a theory's conception of the corporate actor satisfies these conditions, laboratory experiments provide simultaneously maximally rigorous and statistically conservative tests.

\section{a. There are Two Alternative Choices}

Given the purposive nature of corporate actors, a larger number of choices can be handled by considering two at a time, and the Condorcetian cycles will not occur. When the group is small, then all members have to share common goals such that, in light of full information, all members would agree on which is the superior choice. Such agreement is not necessary when the group is large, however.

\section{b. The Mean Individual Capability to Make the Right Decision is} At Least 0.50

While heterogeneous groups perform better than homogeneous ones, their mean individual competence must be slightly higher $\left(\frac{1}{2}+\frac{1}{2 n}\right)$.

\section{c. Individual Decisions are Not Too Highly Positively Correlated}

Negative correlations are conducive to superior collective decisions. Deference to external opinion leaders does not violate independence of decisions as long as $p_{i}>f_{i}$. Deference to internal opinion leaders preserves the CJT as long as the number of such opinion leaders is small relative to $n$.

\section{d. Collective Decision Rule is Simple Majority}

If the group uses supermajority rule, the mean individual competence must be higher.

\section{What About External Validity?}

One of the most common criticisms of laboratory experiments is the lack of external validity. Critics often charge that laboratory experiments 
have weak external validity. This is false; laboratory experiments have no external validity.

External validity is the extent to which one can generalize one's empirical findings to a larger population of interest (Campbell and Stanley 1963: 5). This is not the purpose of conducting laboratory experiments, however; one never generalizes the empirical findings from laboratory experiments to a larger population of interest. As many in the past have argued (Zelditch 1969; Webster and Kervin 1971; Greenwood 1982; Martin and Sell 1979; Mook 1983; Webster 1994), the purpose of conducting laboratory experiments instead is to test a general and abstract theory with clearly stated scope conditions, and, once supported, it is the theory, not the experimental data, that is generalized to natural settings of interest that meet its scope conditions.

Figure 1 summarizes the proper design of experimental research. First, the general and abstract theory to be tested in a laboratory experiment must have a set of clearly stated scope conditions under which the theory is meant to apply. Then the researcher must carefully design a laboratory experiment so that it meets all of the scope conditions of the theory being tested. The theory and its scope conditions therefore specify the design of the experiment. As Webster and Kervin (1971: 267) point out, a laboratory experiment carefully designed to meet all the scope conditions of the theory is no more than one empirical instance of what the theory explains. However, it is also no less. It is therefore as good a test of the theory as any other empirical instance that meets all of its scope conditions.

A laboratory experiment thus designed and properly conducted provides a rigorous test of the theory and either supports or rejects it. If the experiment supports the theory, it is the theory (which is more credible now that it has experimental support) that is then generalized to events in natural settings that meet the theory's scope conditions, and the theory would explain such events. Since the experimental data are never

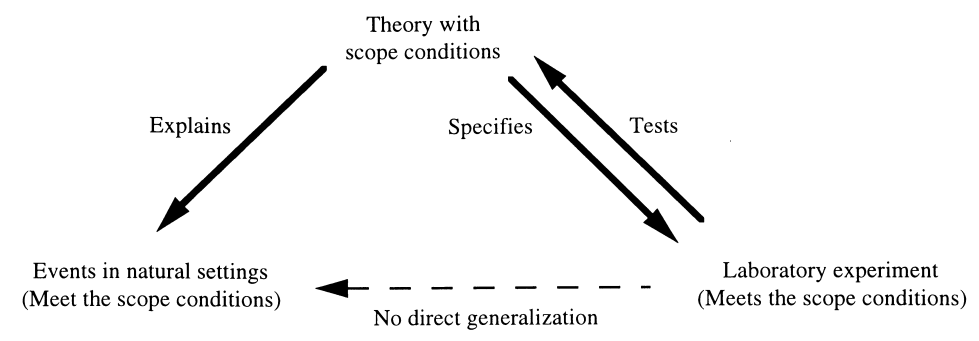

Figure 1. Proper design of experimental testing 
directly generalized to the events in natural settings (as indicated by the absence of an arrow from the experiment to the natural settings), external validity is not an issue for laboratory experiments.

While others have adequately and conclusively dealt with this issues of 'artificiality' or 'external validity' elsewhere (Zelditch 1969; Webster and Kervin 1971; Greenwood 1982; Martin and Sell 1979; Mook 1983; Webster 1994), there has been a new criticism of laboratory experiments that has not so far been dealt with to my knowledge. While these critics (Borgatta and Bohrnstedt 1974; Smith 1990) call it an 'external validity problem', I believe it can better be characterized as a problem of hidden interaction effects.

Smith (1990) illustrates this problem with actual empirical data he collected from a random sample of college seniors at 14 colleges and universities in the Philadelphia metropolitan area. Respondents were asked to estimate the annual income of a manager at a fictitious fast food restaurant in a local mall. Different versions of the vignette systematically varied the personal characteristics of the manager in sex (male or female), education (10th grade or college education) and age (24 or 34 years). Table 1 presents the effects of these manipulations on the estimated annual income of the manager, broken down by the sex of the respondent.

Men and women responded to the sex and education manipulations similarly: they both thought that sex would not have any effect on the

Table 1. The effects of personal characteristics of the manager on estimated annual income, by the sex of the respondent ( $t$-statistic)

\begin{tabular}{lccc}
\hline & \multicolumn{3}{c}{ Sample } \\
\cline { 2 - 4 } Characteristic & All & Male & Female \\
\hline Sex (male) & 290 & 163 & 1123 \\
& $(0.34)$ & $(0.16)$ & $(0.76)$ \\
Education (years) & 1117 & 1002 & 1490 \\
& $(7.81)$ & $(6.15)$ & $(5.63)$ \\
Age (years) & 170 & $363^{*}$ & $-132^{*}$ \\
& $(1.95)$ & $(3.62)$ & $(-0.84)$ \\
Constant & 2.575 & -2003 & 6835 \\
& $(0.86)$ & $(-0.54)$ & $(1.40)$ \\
d.f. & 378 & 230 & 144 \\
$R^{2}$ & 0.159 & 0.191 & 0.183 \\
SEE & 8076 & 7351 & 8730 \\
\hline
\end{tabular}

Note: Data have been weighted to adjust for the oversampling of students from smaller schools

*Coefficients are statistically significantly different from each other $(p<0.01)$

Source: Smith (1990: 66). 
annual income of the manager at a fast food restaurant, and they both thought that education would have a significantly positive effect on it. However, men and women responded differently to the age manipulation: men thought that, ceteris paribus, an older manager would earn significantly more, while women estimated that an older manager would earn less (albeit not statistically significant). The difference between the coefficients for men and women for this manipulation is statistically significant at the 0.01 level.

Smith's point is this: if one's hypothesis is that people estimate that age affects earnings positively, and tested it in a laboratory experiment, then the result of the test would depend on who the subjects are. If they are men, the hypothesis will be confirmed; if they are women, it will be disconfirmed. Now if the crucial subject characteristic was something mundane like sex, the solution is easy. We routinely include both men and women among our subjects, and, had we suspected that subject's sex might make a difference, we might even block on sex to partial out its effect.

However, Smith's criticism is more fundamental: what if the treatment effects interact with some unknown subject characteristics? What if the theory posits that $X$ has an effect on $Y$ [Figure 2 (a)], whereas the truth is that $X$ and $Z$ have an interaction effect on $Y$ [Figure 1 (b)] and $Z$ strongly correlates with some characteristics of our typical subject population ('college sophomores'), such as SES, education or cognitive abilities? Then, Smith contends, we would never be able to uncover the important interaction effect of $Z$ on $Y$ in our laboratory experiments,

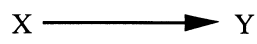

(a)

The Theory

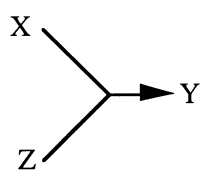

(b)

The Truth

Figure 2. A hidden interaction effect 
because there is no variation in $Z$ among our subjects, whereas we would be able to discover it if we use a nationally representative sample.

Smith's criticism is problematic for two reasons. First, Smith and his fellow critics of laboratory experiments would not be able to discover the interaction effect of $Z$ with their nationally representative sample unless they had thought to include $Z$ as a variable both in their data and in their regression equation. How would they know to do this? If their suspicion that $Z$ might make a difference had come from a well-articulated theory, then it can be tested in a laboratory experiment.

Second, while Smith's observation is true, it is not a valid criticism of laboratory experiments, if one subscribes to Lakatos' (1970) sophisticated methodological falsificationism. For, in this view, data cannot falsify a theory; only a better theory can. Even data collected from a nationally representative sample are still data, and as such cannot falsify a theory by themselves. If the only currently available theory of phenomenon $Y$ is the one presented in Figure 2 (a), and if it has experimental support, then it must remain the currently and provisionally accepted theory of $Y$, even though it is misspecified ${ }^{11}$ and is not perfectly consistent with the truth represented in Figure 1 (b). It must remain the provisionally accepted theory until and unless someone proposes an alternative theory that includes the interaction effect of $Z$. When alternative theories are available, one still cannot do better in an attempt to adjudicate between the two and get to the truth than to test the competing theories in the most rigorous manner-in a laboratory experiment.

Laboratory experiments are not methods of discovery (Cohen 1989: 239-64). Without a general and abstract theory with clearly stated scope conditions, they cannot tell us anything other than how some 'college sophomores' behave in a given highly artificial setting; they are completely useless. 'However, with a theory, experiments are unmatched as a means to assess and improve the theory' (Webster 1994: 61). I therefore advocate their use, not only to test theories of individual behavior, as has hitherto been done, but also to test theories of corporate behavior.

\section{Inferiority of Supermajority Decision Rules}

Finally, I would like to comment on one important implication of the extension of the CJT presented above: the relaxation of Condition 5 (Kanazawa 1998: Theorem 2). It is commonly believed that larger majorities are more likely to be right than a simple majority. Collectivities often require supermajorities for decisions that they deem 
more important and grave in their consequences. For instance, the US Senate requires a two-thirds majority for important matters (such as the conviction of impeached Federal officials or the change in Senate rules) while it only requires a simple majority for routine decisions (such as passing a resolution or a piece of legislation). Similarly, criminal juries require unanimity to convict the defendant while civil juries require only a three-quarters majority to find liability. This is because criminal conviction is considered to be a more serious matter than a civil liability.

Kanazawa's (1998) Theorem 2, however, demonstrates that the average competence of individuals must be higher with supermajority rules for the CJT to hold. Since the average competence of individuals remains constant regardless of the collective decision rules (for instance, we have the same 100 senators and their competences whether they use a simple majority rule or a two-thirds majority rule), then it follows that the CJT is less likely to hold, and the collectivity is less likely to make the right decision, when it uses a supermajority rule. A direct (if somewhat counterintuitive) implication of Kanazawa's (1998) Theorem 2 is that, ceteris paribus, the US Senate is more likely to make the wrong decision precisely when it wants to be more cautious, and criminal juries are more likely to reach a wrong verdict than civil juries. ${ }^{12}$ Collectivities are more likely to make the right decision with a simple majority rule than with a supermajority rule.

\section{Conclusion}

The CJT and its extensions demonstrate that, under reasonable conditions, collective decisions are always superior to individual decisions. Then under these conditions, corporate actors are more likely to make the right decisions than individual actors. I argue that laboratory experiments, in which human subjects play the role of corporate actors, provide a statistically conservative test of the theory of corporate behavior because such a test underestimates the probability that the corporate actors in the natural settings will make the right decision under similar circumstances. Combined with its rigor, experimental testing of theories of corporate behavior should therefore be preferred to non-experimental testing, as long as the theory being tested assumes that the corporate actors are purposive (typical in rational choice theories). The theory being tested, however, must also have a set of clearly stated scope conditions in order to avoid the problem of external validity. As long as the theory has clearly stated scope conditions, it is the theory, not the exper- 
imental data, that is generalized to events in natural settings that also meet the scope conditions, and external validity (the problem of generalizability of empirical findings) ceases to be a concern.

\section{NOTES}

I thank David M. Estlund, Heather A. Haveman, Michael Hechter, Douglas D. Heckathorn, Christine Horne, Edgar Kiser, Krishna K. Ladha, Sarah A. Soule, Michael W. Macy, Linda D. Molm, James Ranger-Moore, Martin T. Wells, Joseph M. Whitmeyer, David Willer and Morris Zelditch, Jr for their comments on earlier drafts of this paper.

1. Some social scientists, especially in the area of comparative and historical sociology, eschew general and abstract theories and prefer instead to construct historically and geographically specific explanations (Skocpol and Somers 1980; Quadagno and Knapp 1992). By its very nature, the laboratory experiment in social sciences is only capable of testing general and abstract theories (Zelditch 1969; Martin and Sell 1979), whether micro or macro. However, the laboratory experiment will still be useful in comparative and historical sociology if hypotheses are derived from general and abstract theories (Kiser and Hechter 1991).

2. Some theories of corporate behavior have been tested in laboratory experiments. Zucker (1977) examines the process of cultural transmission within organizations, Coursey et al. (1984a,b) test theories of firms' entry into market, and Beer et al. (1987) study conflict between nation states. However, in all of these cases, human subjects play the role of individuals. Human subjects in Zucker's (1977) experiments are members of (two-person) organizations, those in Coursey et al. (1984a,b) are managers who actually make the decision for the firms whether or not to enter a particular market, and those in Beer et al. (1987) are national leaders who set foreign policies and directly deal with foreign countries. My point here is that human subjects in laboratory experiments have never played the role of corporate actors per se (organizations rather than organizational members, firms rather than managers, nations rather than national leaders).

3. In exchange theory, 'an actor can be either a person or a group' (Emerson 1962: 32) as long as '(1) it confronts its environment as a single (social) unit, and (2) it is dealt with by actors in the environment as a single unit' (Emerson 1981: 46). In game theory, 'the player is perforce the basic decision unit of the game. He is also the basic evaluation unit. In economic models he may be an individual consumer, a household, a firm or financial institution, a manager, a labor union, a government agency, or even a whole nation or its leader' (Shubik 1982: 18). Nodes in network analysis 'might represent, for example, participants in a peasant market, a group of friends, or a set of companies who might do business with one another' (Heckathorn 1979: 232).

4. I thank Douglas D. Heckathorn and Christine Horne for independently suggesting this idea to me.

5. There are some exceptions to this generalization. Corporate actors involved in social movements and other collective behavior (such as mobs and riots) execute their decisions qua corporate actors, through multiple (often numerous) individuals rather than a singular agent on behalf of the group. Such corporate actors (and theories about them) lie outside the scope of the methodology I advocate here. I thank Edgar Kiser for making this point to me. 
6. This does not mean that agents always faithfully carry out the decisions and wishes of the principals. The extent to which agents do so is a variable, affected by various external conditions. The point is that the agent in theory and in natural settings is the same as the subject in the experimental test; both are individuals. Then human subjects can be used to test causal hypotheses about agents' behavior in a laboratory experiment. Causal hypotheses about corporate actors' decision making (the main focus of this paper) and those about their decision execution (via agents) must thus be tested in separate experiments.

7. There is a third ideal type of groups: oligarchical groups, where a small subset of the group (the oligarchs) makes the decision for the group. However, one can think of the oligarchs as a small democratic group within a larger group; the group decisions reflect the individual decisions of all oligarchs. Thus, if I can justify the use of human subjects to model the process of decision making within democratic groups of all sizes, then I can justify the use of human subjects for the same process within oligarchical groups.

8. In fact, Chapter 7 of Arrow's Social Choice and Individual Values (1963) mostly discusses how his famous conclusion, that there is no satisfactory general social welfare function, does not hold when citizens share certain common preference orderings.

9. I follow Black (1958: 164-5) and use the terms 'right' and 'wrong' without any moral or other implications. Decisions are 'right' or 'wrong' only relative to group goals. 'Right' decisions are efficacious with respect to such goals, and 'wrong' ones are inefficacious. I choose to use right/wrong, rather than efficacious/inefficacious or other more descriptive terms, purely for their simplicity. While I will not put these terms in quotation marks below, the reader should always remember that the terms are mere shorthand. Further, the right/wrong dimension is continuous, not dichotomous; I use the dichotomous labels for ease of presentation.

10. Technically, it must be that $\bar{r}<\bar{p}-\frac{n}{n-1} \frac{(\bar{p}-0.25) \bar{q}}{\bar{p}} \equiv r^{*}(n, \bar{p})$, where $r_{i j}=$ the probability that individuals $i$ and $j$ simultaneously make the right decision $\left(=p_{i} p_{j}\right.$ if the decisions are independent); $\bar{r}=\sum_{i}^{n} \sum_{j \neq i}^{n} r_{i j} / n(n-1), \bar{p}=\sum_{i}^{n} p_{i} / n$, and $\bar{q}=1-\bar{p}$ (see Ladha 1992: Appendix, for proof).

11. The fact that a theory is misspecified in itself is not a valid criticism of it. For until there is one general theory that explains everything in the universe, all existing theories of any phenomenon are partial and therefore misspecified in some (albeit unknown) way. The question is not whether a theory is true or false in some absolute sense (if it was, then all theories are false), but which among the alternative theories is the truer or the truest. The truest of all currently available theories must remain the accepted theory until an even truer one comes along (Popper 1994).

12. Of course, from the perspective of the CJT, juries have another problem: deliberation. Deliberation makes individual jurors' decisions interdependent through interpersonal influence, and makes the CJT less likely to hold (unless it creates factions and makes individual decisions negatively correlated).

\section{REFERENCES}

Abell, P. 1989. 'Games in Networks: A Sociological Theory of Voluntary Associations.' Rationality and Society 1: 259-82.

Ainslie, G. 1992. Picoeconomics: The Strategic Interaction of Successive Motivational States Within the Person. Cambridge: Cambridge University Press. 
Arminger, G. and G.W. Bohrnstedt. 1987. 'Making it Count Even More: A Review and Critique of Stanley Lieberson's Making It Count: The Improvement of Social Theory and Research.' In Sociological Methodology, Vol. 17, ed. C.C. Clogg. pp. 363-72. Washington DC: American Sociological Association.

Aronson, E., M. Brewer and J.M. Carlsmith. 1985. 'Experimentation in Social Psychology.' In Handbook of Social Psychology, Vol. 1, 3rd edn, ed. G. Lindzey and E. Aronson, pp. 441-86. New York: Random House.

Arrow, K.J. 1963. Social Choice and Individual Values, 2nd edn. New Haven, CT: Yale University Press.

Beer, F.A., A.F. Healy, G.P. Sinclair and L.E. Bourne, Jr. 1987. 'War Cues and Foreign Policy Acts.' American Political Science Review 81: 701-15.

Berger, J., D.P. Eyre and M. Zelditch, Jr. 1989. 'Theoretical Structures and the Micro/Macro Problem.' In Sociological Theories in Progress, Vol. 3, ed. J. Berger, M. Zelditch, Jr and B. Anderson, pp. 11-32. Boston, MA: Houghton Mifflin.

Berk, R.A. 1988. 'Causal Inference for Sociological Data.' In Handbook of Sociology, ed. N.J. Smelser, pp. 155-72. Beverly Hills, CA: Sage.

Black, D. 1958. The Theory of Committees and Elections. Cambridge: Cambridge University Press.

Boland, P.J. 1989. 'Majority Systems and the Condorcet Jury Theorem.' The Statistician 38: 181-89.

Borgatta, E.F. and G.W. Bohrnstedt. 1974. 'Some Limitations on Generalizability from Social Psychological Experiments.' Sociological Methods and Research 3: 111-20.

Campbell, D.T. and J.C. Stanley. 1963. Experimental and Quasi-experimental Designs for Research. Boston, MA: Houghton Mifflin.

Cohen, B.P. 1989. Developing Sociological Knowledge: Theory and Method, 2nd edn. Chicago, IL: Nelson-Hall.

Condorcet, Marquis de. 1785. Essai sur l'application de l'analyse à la probabilité des décisions rendues à la pluralité des vox. Paris: Imprimerie Royale.

Condorcet, Marquis de. 1976. Condorcet: Selected Writings, ed. K.M. Baker. Indianapolis, IN: Bobbs-Merrill.

Cook, T.D. and D.T. Campbell. 1979. Quasi-Experimentation: Design and Analysis Issues for Field Settings. Boston, MA: Houghton Mifflin.

Costner, H.L. and R.K. Leik. 1964. 'Deductions from "Axiomatic Theory."' American Sociological Review 29: 819-35.

Costner, H.L. and H.M. Blalock. 1972. 'Scientific Fundamentalism and Scientific Utility: Reply to Gibbs.' Social Science Quarterly 52: 827-44.

Coursey, D.R. M. Isaac and V.L. Smith. 1984a. 'Natural Monopoly and Contested Markets: Some Experimental Results.' Journal of Law and Economics 27: 91-113.

Coursey, D.R. M. Isaac, M. Luke and V.L. Smith. 1984b. 'Market Contestability in the Presence of Sunk (Entry) Costs.' Rand Journal of Economics 15: 69-84.

Elster, J. 1989. The Cement of Society: A Study of Social Order. Cambridge: Cambridge University Press.

Emerson, R.M. 1962. 'Power-dependence Relations.' American Sociological Review. 27: $31-41$.

Emerson, R.M. 1981. 'Social Exchange Theory.' In Social Psychology: Sociological Perspectives, ed. M. Rosenberg and R.H. Turner, pp. 30-65. New Brunswick, NJ: Transaction Publishers.

Estlund, D.M. 1994. 'Opinion Leaders, Independence, and Condorcet Jury Theorem.' Theory and Decision 36: 131-62. 
Feld, S.L. and B. Grofman. 1990. 'Collectivities as Actors: Consistency of Collective Choices.' Rationality and Society 2: 429-48.

Friedman, D. 1986. 'The Principal-Agent Problem in Labor-Management Negotiations.' In Advances in Group Processes, Vol. 3, ed. E.J. Lawler, pp. 89-106. Greenwich, CT: JAI Press.

Garman, M.B. and M.I. Kamien. 1968. 'The Paradox of Voting: Probability Calculations.' Behavioral Science 13: 306-23.

Gehrlein, W.V. and P.C. Fishburn. 1976. 'The Probability of the Paradox of Voting: A Computable Solution.' Journal of Economic Theory 13: 14-25.

Greenwood, J.D. 1982. 'On the Relation Between Laboratory Experiments and Social Behaviour: Causal Explanation and Generalization.' Journal for the Theory of Social Behavior 12: 225-50.

Grofman, B. and S.L. Feld. 1988. 'Rousseau's General Will: A Condorcetian Perspective.' American Political Science Review 82: 567-76.

Heckathorn, D. 1979. 'The Anatomy of Social Network Linkages.' Social Science Research 8: 222-52.

Holland, P.W. 1986. 'Statistics and Causal Inference.' Journal of the American Statistical Association 81: 945-60.

Jensen, M.C. and W.H. Meckling. 1976. 'Theory of the Firm: Managerial Behavior, Agency Costs and Ownership Structure.' Journal of Financial Economics 3: 305-60.

Kanazawa, S. 1998. 'A Brief Note on a Further Refinement of the Condorcet Jury Theorem for Heterogeneous Groups.' Mathematical Social Sciences 35: 69-73.

Kiser, E. and M. Hechter. 1991. 'The Role of General Theory in Comparative-Historical Sociology.' American Journal of Sociology 97: 1-30.

Ladha, K.K. 1992. 'The Condorcet Jury Theorem, Free Speech, and Correlated Votes.' American Journal of Political Science 36: 617-34.

Ladha, K.K. 1995. 'Information Pooling through Majority-rule Voting: Condorcet's Jury Theorem with Correlated Votes.' Journal of Economic Behavior and Organization 26: 353-72.

Lakatos, I. 1970. 'Falsification and the Methodology of Scientific Research Programmes.' In Criticism and the Growth of Knowledge, ed. I. Lakatos and A. Musgrave, pp. 91-196. Cambridge: Cambridge University Press.

Lawler, E.J., C. Ridgeway and B. Markovsky. 1993. 'Structural Social Psychology and the Micro-Macro Problem.' Sociological Theory 11: 268-90.

Martin, M.W. and J. Sell. 1979. 'The Role of the Experiment in the Social Sciences.' Sociological Quarterly 20: 581-90.

McLean, I. and F. Hewitt. 1994. Condorcet: Foundations of Social Choice and Political Theory. Brookfield, NS: Edward Elgar.

Miller, N.R. 1986. 'Information, Electorates, and Democracy: Some Extensions and Interpretations of the Condorcet Jury Theorem.' In Information Pooling and Group Decision Making: Proceedings of the Second University of California, Irvine, Conference on Political Economy, ed. B. Grofman and G. Owen, pp. 173-92. Greenwich, CT: JAI Press.

Mook, D.G. 1983. 'In Defense of External Invalidity.' American Psychologist 38: 379-87.

Niemi, R.G. and H.F. Weisberg. 1968. 'A Mathematical Solution for the Probability of the Paradox of Voting.' Behavioral Science 13: 317-23.

Petersen, T. 1993. 'The Economics of Organization: The Principal-Agent Relationship.' Acta Sociologica 36: 277-93. 
Plott, C.R. 1967. 'A Notion of Equilibrium and its Possibility Under Majority Rule.' American Economic Review 57: 787-806.

Popper, K.R. 1994. 'Models, Instruments, and Truth: The Status of the Rationality Principle in the Social Sciences.' In The Myth of the Framework: In Defense of Science and Rationality, ed. M.A. Notturno, pp. 154-84. London: Routledge.

Quadagno, J. and S.J. Knapp. 1992. 'Have Historical Sociologists Forsaken Theory? Thoughts on the History/Theory Relationship.' Sociological Methods and Research 20: 481-507.

Schelling, T.C. 1984. Choice and Consequence. Cambridge, MA: Harvard University Press.

Shubik, M. 1982. Game Theory in the Social Sciences: Concepts and Solutions. Cambridge, MA: MIT Press.

Skocpol, T. and M. Somers. 1980. 'The Uses of Comparative History in Macrosocial Inquiry.' Comparative Studies in Society and History 22: 174-97.

Skog, O.-J. 1993. 'The Voting Paradox in Socially Integrated Populations.' Acta Sociologica 36: 207-22.

Smith, H.L. 1990. 'Specification Problems in Experimental and Nonexperimental Social Research.' In Sociological Methodology, Vol. 20, ed. C.C. Clogg, pp. 59-91. Washington DC: American Sociological Association.

Sobel, M.E. 1996. 'An Introduction to Causal Inference.' Sociological Methods and Research 24: 353-79.

Webster, Jr, M. 1994. 'Experimental Methods.' In Group Processes: Sociological Analyses, ed. M. Foschi and E.J. Lawler, pp. 43-69. Chicago, IL: Nelson-Hall.

Webster, Jr, M. and J.B. Kervin. 1971. 'Artificiality in Experimental Sociology.' Canadian Review of Sociology and Anthropology 8: 263-72.

Zelditch, Jr, M. 1969. 'Can You Really Study an Army in the Laboratory?' In A Sociological Reader on Complex Organizations, ed. A. Etzioni, pp. 528-39. New York: Holt, Rinehart and Winston.

Zucker, L.G. 1977. 'The Role of Institutionalization in Cultural Persistence.' American Sociological Review 42: 726-43.

SATOSHI KANAZAWA is Assistant Professor of Sociology at Indiana University of Pennsylvania. His current work focuses on the introduction of evolutionary psychology into rational choice theory and sociology in general. His recent articles either have appeared or are forthcoming in Mathematical Social Sciences, Sociological Theory, Journal of Politics, Social Science Research, Journal of Political and Military Sociology (with Debra Friedman), Social Forces (with Mary C. Still) and American Sociological Review. His book (with Alan S. Miller) on social order in Japan is forthcoming from Westview Press.

ADDRESS: Department of Sociology, Indiana University of Pennsylvania, Indiana, PA 15705-1087, USA. 